Systematic Review

\title{
Peningkatan Kompetensi Mahasiswa Keperawatan Melalui Strategi Pembelajaran Berbasis Virtual Reality
}

\author{
Ike Puspitaningrum¹, Rr. Sri Endang Pujiastuti², Kurniati Puji Lestari ${ }^{3}$
}

1,2,3 Politeknik Kesehatan Kemenkes Semarang

\begin{tabular}{|c|c|}
\hline Article Info & Abstract \\
\hline $\begin{array}{l}\text { Article History: } \\
\text { Diterima } 8 \text { Oktober } 2019 \\
\text { Key words: } \\
\text { Learning methods; } \\
\text { Millennial; Virtual } \\
\text { Simulation; Virtual Reality }\end{array}$ & $\begin{array}{l}\text { Nursing higher education has new challenges to prepare nursing students as } \\
\text { agents of change in the era of the industrial revolution } 4.0 \text {. Nursing students } \\
\text { today are millennial and Z generation with unique needs and ways of } \\
\text { learning. Students more interested in digital-based learning media. Digital- } \\
\text { based learning methods were an urgent need to be developed to provide } \\
\text { solutions to the learning needs of the millennial generation. The systematic } \\
\text { review aimed to discuss the use of VR technology for educating the nursing } \\
\text { student. The databases searched included: PubMed, Springerlink and } \\
\text { Proquest from the years } 2015 \text { to } 2019 \text { with the keywords virtual reality, } \\
\text { virtual simulation, simulation technology, immersive learning. The inclusion } \\
\text { criteria included: articles published in the English language, student } \\
\text { respondents and randomized controlled trial (RCT) research methods. The } \\
\text { results of article was identified and reviewed by } 3 \text { researchers. Researchers } \\
\text { approved } 158 \text { titles of article that match the keywords without duplicates } \\
\text { and } 5 \text { articles that match the inclusion criteria. Four articles discuss the } \\
\text { students' competencies when using virtual simulations compared with the } \\
\text { manikin simulated. The results showed an increase in psychomotor skills, } \\
\text { communication, and knowledge. Self-confidence increases, learning } \\
\text { satisfaction and anxiety levels decrease. Two articles discuss the analysis of } \\
\text { the unit cost, which states that the virtual simulation has cost utility ratio } \\
\text { more profitable compared with the Manikin simulations. The results of the } \\
\text { systematic review showed that virtual reality was relevant method as a } \\
\text { learning strategy to enhance students' competencies and have more } \\
\text { profitable costs compared to conventional methods. }\end{array}$ \\
\hline
\end{tabular}

\section{PENDAHULUAN}

Generasi milenial sangat lekat dengan penggunaan produk teknologi, menghabiskan sebagain besar waktunya di dunia maya, akses informasi menggunakan smartphone, memiliki pengetahuan yang tinggi dalam penggunaan platform dan perangkat mobile (Kominfo, 2016). Penggunaan teknologi up to date dalam proses pembelajaran sudah mulai banyak diaplikasikan di perguruan tinggi kesehatan.

Virtual reality (VR), augmented reality (AR), dan teknologi mixed reality (MR)

\footnotetext{
Corresponding author:

Ike Puspitaningrum

ike.puspitaningrum@gmail.com

Jurnal Kepemimpinan dan Manajemen Keperawatan, Vol 2 No 2, November 2019

DOI: http://dx.doi.org/10.26594/jkmk.v2.i2.379

e-ISSN 2621-5047
} 
memungkinkan mahasiswa berinteraksi dengan komponen yang ditampilkan secara virtual dalam lingkungan virtual dan fisik. Kombinasi komponen fisik dan virtual memungkinkan mahasiswa untuk mempraktikkan skenario kasus klinis dengan aman baik di kelas maupun di laboratorium. Penelitian tentang penggunaan perangkat teknologi imersif menunjukkan adanya efek positif pada kepercayaan diri mahasiswa keperawatan (Vaughn et al. 2016). Inovasi di bidang teknologi imersif memberikan alternatif baru yang menjanjikan untuk simulasi berkualitas tinggi dengan harga terjangkau. Simulasi dengan cara konvensional dinilai membutuhkan biaya pelaksanaan dan perawatan alat yang lebih mahal.

Simulasi virtual klinis menggunakan pasien virtual dalam lingkungan klinis yang dinamis. Konsep ini didasarkan pada pasien virtual yang diakses melalui berbagai multimedia, interaktif berbasis layar (Berman; Durning; Fischer; Huwendiek; Triola, 2016). Teknologi digital dan virtual dapat menciptakan situasi nyata menggunakan pasien virtual yang digambarkan pada layar sentuh (Lopreiato, 2016). Perkembangan teknologi digital dan virtual telah memberikan solusi terhadap kesulitan pembelajaran langsung pada pasien.

Simulasi virtual klinis meningkatkan interaksi dan umpan balik dan meningkatkan persepsi efikasi diri dan tingkat kepuasan pengguna (Roh; Lee; Chung; Park, 2013). Penggunaan virtualisasi klinis meningkatkan kinerja dan kompetensi yang terkait dengan keterampilan psikomotorik (Wilson-Sands; Brahn; Graves, 2015), berpikir kritis, keterampilan klinis (Liaw; Wong; Chan; Ho; Mordiffi; Ang, 2015), dan pengambilan keputusan (Berman; Durning; Fischer; Huwendiek; Triola, 2016). Kemajuan teknologi terbaru dalam simulasi virtual klinis telah meningkatkan realisme dan interaksi dinamis, dengan kemungkinan digambarkan pada tabel layar sentuh atau
Web (Meakim; Boese; Decker; Franklin; Gloe; Lioce, 2013). Namun, saat ini metode pembelajaran labratorium dengan media virtual masih perlu dikembangkan sesuai dengan kebutuhan mahasiswa keperawatan di era teknologi ini untuk mencapai kepuasan belajar mahasiswa dan hasil belajar yang efektif. Tujuan dari review ini secara sistematis meninjau hasil-hasil penelitian yang berkaitan dengan penggunaan teknologi VR dalam pembelajaran laboratorium mahasiswa keperawatan.

\section{METODE}

Pencarian literature melalui PubMed, Springerlink dan Proquest pada rentang tahun 2015-2019. Kata kunci yang digunakan adalah virtual reality, virtual simulation, simulation technology, immersive learning. Kriteria inklusi yang ditetapkan meliputi: artikel berbahasa inggris, responden mahasiswa dan metode penelitian menggunakan randomised control trial (RCT). Hasil pencarian literature diidentifikasi dan direview oleh 3 peneliti.

\section{HASIL}

Peneliti mengidentifikasi 1848 judul artikel yang sesuai dengan kata kunci dan 158 artikel tanpa duplikasi dan 5 artikel yang sesuai dengan kriteria inklusi dan eksklusi. Empat artikel membahas tentang kompetensi yang dicapai mahasiswa ketika menggunakan simulasi virtual dibandingkan dengan simulasi manikin. Hasil penelitian menunjukkan peningkatan ketrampilan psikomotorik, komunikasi, dan pengetahuan. Kepercayaan diri meningkat, kepuasan belajar dan tingkat kecemasan menurun. Dua artikel membahas tentang analisis unit cost, yang menyatakan bahwa simulasi virtual memiliki rasio utilitas biaya yang lebih menguntungkan dibandingkan dengan simulasi manikin. 


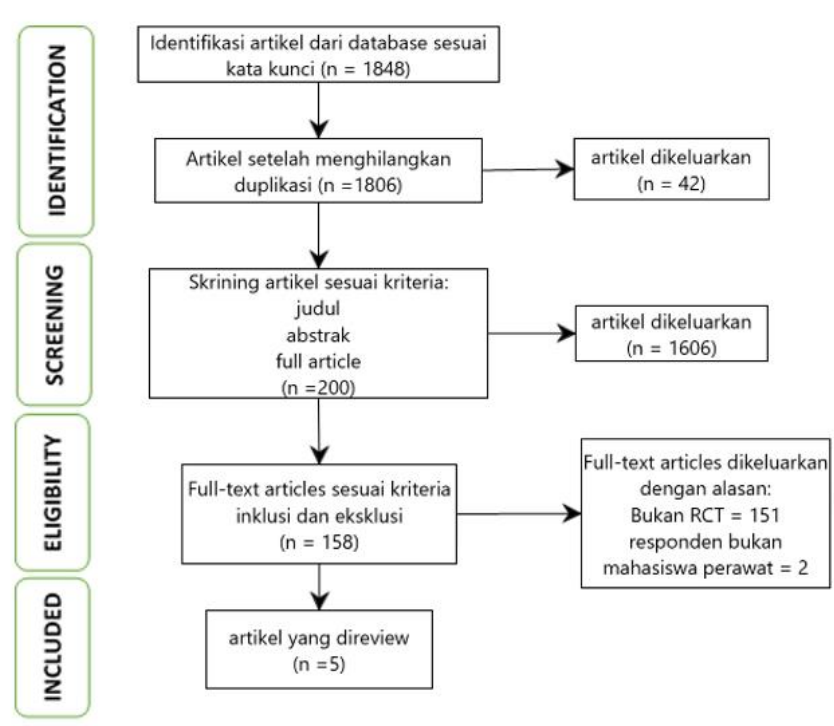

Gambar 1

Proses literature review

\section{PEMBAHASAN}

Perkembangan dalam teknologi digital dan virtual telah memudahkan cara menciptakan realitas dengan menggunakan pasien virtual (Lopreiato, 2016) yang digambarkan pada layar sentuh komputer (simulasi virtual klinis). Simulasi virtual klinis adalah kondisi dan situasi dari kenyataan yang digambarkan di layar komputer, dan melibatkan orang-orang nyata yang mengoperasikan sistem simulasi. Ini adalah jenis simulasi yang menempatkan orang dalam peran sentral melalui latihan pengambilan keputusan, kontrol motorik, dan keterampilan komunikasi (McGaghie, et.al, 2010). Simulasi virtual klinis menggunakan pasien virtual dalam lingkungan klinis yang dinamis dan imersif. Konsep ini didasarkan pada pasien virtual yang diakses melalui berbagai multimedia, interaktif berbasis layar (Berman, 2016). Simulasi virtual klinis meningkatkan interaksi dan umpan balik, meningkatkan persepsi efikasi diri dan tingkat kepuasan mahasiswa (Chang, 2002; Roh, 2013). Penggunaan simulasi virtual klinis dalam pengembangan kompetensi keperawatan meningkatkan kinerja (Tsai, 2008) dan kompetensi yang terkait dengan keterampilan psikomotorik (WilsonSands,et.al, 2015), pemikiran kritis
(Johnson et.al, 2010), keterampilan klinis (Liaw, 2015) dan pengambilan keputusan (Berman, 2016). Kemajuan teknologi terbaru dalam simulasi virtual klinis telah meningkatkan realisme dan interaksi dinamis, dengan skenario klinis yang digambarkan pada tabel layar sentuh atau di Website.

Penggunaan simulasi virtual dalam pendidikan keperawatan adalah strategi inovatif dalam bentuk aplikasi yang semakin berkembang. Simulasi virtual digunakan sebagai bentuk pembelajaran klinis yang aman dan serealistis mungkin bagi mahasiswa. Simulasi virtual berguna untuk 1) mempelajari keterampilan baru; 2) mempraktikkan keterampilan yang menyatukan konten, pemikiran tingkat tinggi, dan elemen psikomotorik; 3) media pembelajaran untuk meningkatkan kompetensi dalam hal keterampilan tindakan keperawatan; dan 4) penilaian untuk keterampilan berisiko tinggi. Simulasi virtual klinis dapat memberikan strategi pedagogis dan dapat bertindak sebagai fasilitator dalam retensi pengetahuan, penalaran klinis, peningkatan kepuasan belajar (Padilha, et.al, 2019). Simulasi virtual dapat memberikan pembelajaran dengan situasi lingkungan yang realistik seperti dengan pasien nyata. Hal tersebut dapat meningkatkan pengetahuan, kepercayaan diri dan menurunkan kecemasan pada saat memasuki pembelajaran klinik (Cobbett, 2016).

\section{Dampak simulasi virtual pada kompetensi dan penampilan klinis}

Bentuk simulasi virtual di keperawatan telah membantu menjembatani kesenjangan antara teori dan keputusan klinis dalam memberikan asuhan keperawatan yang bebas risiko bagi pasien dan mahasiswa. Penelitian Padilha (2016) menyatakan bahwa simulasi virtual klinis meningkatkan retensi pengetahuan dan penalaran klinis serta meningkatkan kepuasan mahasiswa dalam pembelajaran. 
Simulasi virtual memungkinkan peningkatan $20,4 \%$ dalam retensi pengetahuan dan penalaran klinis mahasiswa dalam konteks penelitian. Studi ini menunjukkan bahwa simulasi virtual klinis adalah strategi pedagogis yang dikombinasikan dengan strategi briefing, simulasi, dan tanya jawab. Hasil ini menunjukkan kesesuaian simulasi virtual dengan harapan dalam cara belajar generasi saat ini. Efek dari penggunaan simulasi virtual klinis sebagai strategi pedagogis dalam meningkatkan retensi pengetahuan dan penalaran klinis dan tingkat kepuasan siswa menunjukkan kecocokan dengan fitur mahasiswa keperawatan abad kedua puluh satu yang menunjukkan minat pada penggunaan simulasi virtual klinis (Padilha, et.al, 2018). Hasil ini sejalan dengan hasil penelitian lain, di mana penulis menemukan bahwa tingkat pengetahuan (Sperl-Hillen, 2014; Tiffany, 2016) dan kepuasan (Batista, et.al, 2014) pada proses pembelajaran meningkat dengan menggunakan simulasi virtual.

Penelitian ini sejalan dengan studi Berman (2016), simulasi virtual klinis merupakan strategi pembelajaran interaktif yang memberikan motivasi dan kepuasan intrinsik mahasiswa, dan berfokus pada penerapan pengetahuan dasar yang berorientasi pada tantangan pembelajaran klinis. Simulasi virtual klinis dapat berkontribusi dalam mengurangi kesalahan klinis, meningkatkan keselamatan dan kualitas perawatan. Simulasi virtual klinis mengatasi kesulitan dalam mengelola ruang laboratorium, memungkinkan institusi pendidikan untuk menambah jumlah skenario klinis yang tersedia untuk pelatihan mahasiswa. Simulasi virtual klinis, sebuah fitur yang memungkinkan adanya peningkatan luar biasa dalam jumlah mahasiswa yang dapat mengikuti pelatihan individu dan pengurangan yang signifikan dalam biaya simulasi yang digunakan setiap mahasiwa (Padilha, 2019).
Penelitian Cobbett (2016) yang membandingkan simulasi virtual clinical simulation (VCS) dan face-to-face (F2F) mendapatkan kesimpulan bahwa tidak ada perbedaan dalam kepercayaan diri mahasiswa dalam skenario praktik klinis. Hal tersebut berbeda dengan hasil penelitian Fisher dan King (2013) yang menemukan adanya peningkatan kepercayaan diri mahasiswa ketika terlibat dalam simulasi klinis. Tingkat kecemasan mahasiswa lebih tinggi ketika menyelesaikan VCS dibandingkan dengan simulasi F2F. Peningkatan kecemasan muncul dari teknologi pada VCS, sebaliknya, mahasiswa lebih nyaman dalam simulasi F2F karena mayoritas peserta memiliki paparan ke Lab Simulasi sebelumnya. Penelitian Nielson dan Harder (2013) melaporkan area yang akan mengurangi kecemasan mahasiswa selama simulasi meliputi: dukungan fakultas, bimbingan oleh siswa senior, orientasi yang memadai terhadap lingkungan dan peran simulasi, perencanaan asuhan keperawatan sebagai kelompok, dan menghilangkan rekaman video (Nielsen dan Harder, 2013). Setiap skenario dalam kasus menuntut mahasiswa untuk aktif dalam pemecahan masalah pasien virtual, yang dimulai dengan pengumpulan dan pengintegrasian data hasil pengkajian pada pasien virtual yang digunakan untuk merumuskan diagnose dan intervensi keperawatan. Penggunaan pasien virtual dapat meningkatkan kemampuan mahasiswa dalam penalaran klinis (Padilha, 2018).

\section{Dampak simulasi virtual pada biaya}

Dua artikel membahas tentang analisis unit cost, yang menyatakan bahwa simulasi virtual memiliki rasio utilitas biaya yang lebih menguntungkan dibandingkan dengan simulasi manikin. Biaya simulasi berbasis manekin tiga kali lebih tinggi daripada simulasi virtual. Hasil review menunjukkan bahwa virtual reality merupakan metode yang relevan sebagai strategi pembelajaran untuk lebih meningkatkan kompetensi mahasiswa dan 
mempunyai biaya yang lebih menguntungkan dibanding dengan metode konvensional (Haerling, 2018). Simulasi virtual klinis, sebuah fitur yang memungkinkan adanya peningkatan luar biasa dalam jumlah mahasiswa yang dapat mengikuti pelatihan individu dan pengurangan yang signifikan dalam biaya simulasi yang digunakan setiap mahasiwa (Padilha, 2019).

\section{Bentuk simulasi virtual dalam proses pembelajaran}

Simulator virtual klinis dalam penelitian Padilha (2019) menggunakan pasien virtual yang dapat memberikan respon tubuh secara dinamis sesuai dengan intervensi yang diberikan mahasiswa. Skenario klinis dimulai dengan pengarahan; selanjutnya, mahasiswa dapat berinteraksi dengan pasien virtual melalui dialog, memantau parameter fisiologis, observasi dan pemeriksaan fisik, analisis pemeriksaan komplementer, dan intervensi perawatan farmakologis. Tanggapan dan pengembangan kasus klinis bersifat dinamis dan tergantung pada keputusan yang diambil. Penutupan kasus klinis ditentukan oleh keberhasilan penyelesaian skenario atau oleh waktu yang disediakan. Segera setelah simulasi berakhir, akan muncul diagnosis diferensial. Setelah simulasi selesai, simulator menyediakan laporan simulasi, timeline simulasi, dan laporan kinerja. Dalam laporan simulasi, disajikan diagnosis banding yang benar dan pilihan yang dipilih oleh mahasiswa. Semua tindakan yang dilakukan dan konsekuensi hemodinamik disajikan pada satu waktu bersama dengan semua pemeriksaan diagnosis komplementer yang diminta. Dalam laporan simulasi, skor kinerja diberikan untuk 3 kategori informasi, yaitu pemeriksaan fisik, diagnosis, dan terapi. Dalam setiap kategori informasi tersebut, keputusan yang diambil dan kesesuaiannya disajikan. Pada simulator ini terdapat fitur untuk tanya jawab yang menyediakan referensi ilmiah sebagai pendukung skenario klinis dan resolusi optimalnya.
Simulasi pasien virtual yang telah dirancang oleh Liaw (2015) memberikan kesempatan mahasiswa untuk memperoleh pengalaman praktis terkait informasi yang dipelajari. Kondisi umum yang memburuk (yaitu, obstruksi jalan napas, sesak napas, hipotensi, takikardia, oliguria, perubahan kesadaran, dan suhu abnormal) yang terkait dengan kondisi medis akut terdapat dalam lima skenario simulasi yang berkaitan dengan kondisi yang terjadi pada hari yang berbeda pada saat menggunakan pasien virtual untuk pembelajaran. Dalam setiap skenario, mahasiswa berperan sebagai seorang perawat yang menilai dan mengelola pasien virtual yang memburuk dengan memilih tindakan dari menu kontrol ABCDE. Umpan balik langsung diberikan oleh simulator, termasuk perubahan fisiologis, diprogram ke dalam sistem untuk menanggapi intervensi yang telah diberikan oleh mahasiswa. Menu kontrol ISBAR digunakan untuk membantu mahasiswa dalam melaporkan kemunduran pasien virtual. Pada akhir setiap skenario, mahasiswa dapat melakukan tanya jawab untuk membantu mereka merefleksikan pengalaman mereka menyelesaikan kasus klinis pasien virtual. Selain itu, dengan menggunakan alat evaluasi, mahasiswa dapat menerima umpan balik tentang tindakan yang sesuai dan tidak tepat yang diambil dalam skenario simulasi.

Semua mahasiswa menyelesaikan kuesioner tentang informasi demografis dan melakukan pretest kinerja yang terdiri dari penilaian berbasis simulasi yang terjadi di laboratorium simulasi universitas. Identitas mahasiswa dirahasiakan dari penilai dengan mengenakan topi, gaun, dan masker. Mengikuti orientasi pengaturan simulasi, setiap peserta diberikan skenario dengan simulator pasien menampilkan tanda dan gejala perburukan klinis pasien. Setiap mahasiswa diberikan waktu 15 menit untuk menilai dan mengelola simulator pasien yang memburuk. Seluruh proses simulasi direkam pada video. Segera setelah pretest kinerja, para mahasiswa dalam kelompok eksperimen dibawa secara 
individual ke sebuah ruangan dengan set-up komputer untuk melakukan simulasi berbasis web selama 3 jam. Setelah menyelesaikan pembelajaran, para peserta diminta untuk mengisi kuesioner untuk mengevaluasi persepsi mereka tentang simulasi berbasis web. Sekitar satu minggu setelah pretest dan intervensi, para peserta dari kedua kelompok dijadwalkan untuk melakukan posttest kinerja pada penilaian berbasis simulasi secara individual, yang mirip dengan pretest kinerja (Liaw, 2015).

Haerling (2018) mendesain simulasi untuk mahasiswa dalam kelompok simulasi berbasis manekin dan virtual untuk mempersiapkan pengalaman simulasi mereka dengan terlebih dahulu menyelesaikan modul pembelajaran mandiri berbasis komputer. Modul ini memberikan ulasan patofisiologi, farmakologi, dan tindakan keperawatan yang relevan dengan perawatan pasien dengan penyakit paru obstruktif kronis (PPOK). Selanjutnya, mahasiswa dalam kelompok simulasi berbasis manekin menyelesaikan simulasi berbasis manekin langsung, difasilitasi secara profesional dalam kelompok yang terdiri dari dua hingga empat mahasiswa. Mahasiswa dalam kelompok simulasi virtual secara mandiri menyelesaikan simulasi virtual berbasis web yang tersedia. Dalam skenario kasus PPOK, mahasiswa menilai seorang pasien yang telah dirawat dengan kondisi yang memburuk. Dalam skenario, pasien mengalami pneumotoraks. Mahasiswa diharapkan mengenali pneumotoraks, berkolaborasi dengan dokter, dan memulai intervensi keperawatan yang sesuai. Mahasiswa dalam kelompok simulasi berbasis manekin berinteraksi dengan pasien yang disimulasikan fasilitator mereka dan teman sebaya. Mahasiswa dalam kelompok simulasi virtual berinteraksi secara independen dengan pasien simulasi berbasis komputer. Mahasiswa dalam kelompok simulasi berbasis manekin menyelesaikan sesi tanya jawab yang difasilitasi berdasarkan pada model plus / delta. Mahasiswa dalam kelompok simulasi virtual menerima umpan balik yang dihasilkan komputer dari program vSim termasuk peluang untuk perbaikan, catatan rinci tindakan mereka selama skenario, dan skor numerik $(0 \%$ $100 \%)$.

Elif Günay (2017) mengggunakan The VIS System untuk mengajarkan keterampilan pemasangan kateter intravena kepada mahasiswa keperawatan. Sistem VIS adalah simulator VR yang memungkinkan mahasiswa dengan atau tanpa pengalaman pemasangan kateter IV untuk belajar dan mempraktikkan keterampilan psikomotor. VIS menggunakan perangkat haptic, yang memerlukan kontak fisik antara komputer dan mahasiswa, program perangkat lunak, komputer desktop atau laptop, dan penampil anatomi virtual IV. Perangkat haptic meniru lengan pasien dan memiliki celah untuk memasukkan jarum kateter. Setiap aktivitas terdapat sistem sensor, yang dapat mendeteksi gerakan jarum dalam tiga dimensi. Komputer mengubah data ini menjadi gambar VR. Gambar virtual lengan model ditampilkan di layar. Skenario yang dikodekan dalam VIS termasuk struktur vaskular dari berbagai jenis pasien dan peristiwa yang mungkin sering ditemui mahasiswa dalam pengaturan klinis.

\section{SIMPULAN}

Hasil review menunjukkan bahwa virtual reality merupakan metode yang relevan sebagai strategi pembelajaran untuk lebih meningkatkan kompetensi mahasiswa dan mempunyai biaya yang lebih menguntungkan dibanding dengan metode konvensional.

\section{UCAPAN TERIMAKASIH}

Penulis mengucapkan terimakasih kepada semua pihak yang telah mendukung dalam review ini. 


\section{REFERENSI}

Berman NB, Durning SJ, Fischer MR, Huwendiek S, Triola MM. (2016). The role for virtual patients in the future of medical education. Acad Med 2016 Dec;91(9):1217-1222. [doi: 10.1097/ACM.0000000000001146]

[Medline: 26959224]

Chang KK, Chung J, Wong T. (2002). Learning intravenous cannulation: a comparison of the conventional method and the CathSim Intravenous Training System. J Clin Nurs 2002 Jan;11(1):73-78. [Medline: 11845758]

Cobbett, Shelley, Snelgrove-Clarke, Erna. (2016). Virtual verses face to-face clinical simulation in relation to student knoweldge, anxiety, and self-confidence in maternal-newborn nursing: A randomized controlled trial, Nurse Education Today. doi: 10.1016/j.nedt.2016.08.00

Elif Günay I; smailog`lu; Ayten Zaybak. (2017). Comparison of the Effectiveness of a Virtual Simulator With a Plastic Arm Model in Teaching Intravenous Catheter Insertion Skills. Wolters Kluwer Health. DOI: 10.1097/CIN.0000000000000405

Haerling, Katie A. (2018). Cost-Utility Analysis of Virtual and Mannequin-Based Simulation. Sim Healthcare 13 (1) : 34-41, [doi: 10.1097/SIH.0000000000000280]

INACSL Standards Committee. (2016). INACSL standards of best practice: simulation SM debriefing. Clin Simul Nurs 12:S21-S25

Johnson D, Flagg A, Dremsa T. (2010) Effects of using human patient simulator versus a CD-ROM on learning the management of patients exposed to chemical agents. US Army Med Dep J 2010:9-16. [Medline: 21181669]

Liaw SY, Wong L, Chan S, Ho J, Mordiffi S, Ang S, et al. (2015). Designing and evaluating an interactive multimedia web-based simulation for developing nurses' competencies in acute nursing care: randomized controlled trial. J Med Internet Res Jan 12;17(1):e5-10 [FREE Full text] [doi: 10.2196/jmir.3853] [Medline: 25583029]

Lopreiato JO. Agency for Healthcare Research and Quality. (2016). Healthcare Simulation Dictionary URL: https://www.ahrq.gov/sites/default/files/w ysiwyg/professionals/quality-patient- safety/patient-safety-resources/research/ simulation_dictionary/sim-dictionary.pdf

McGaghie WC, Issenberg SB, Petrusa ER, Scalese RJ. (2010). A critical review of simulation-based medical education research: 2003-2009. Med Educ 2010 Jan;44(1):50-63. [doi: 10.1111/j.1365-2923.2009.03547.x] [Medline: 20078756]

Meakim C, Boese T, Decker S, Franklin AE, Gloe D, Lioce L, et al. (2013). Standards of Best Practice: Simulation Standard I: Terminology. Clin Simul Nurs Jun;9(6):S3-S11. [doi: 10.1016/j.ecns.2013.04.001]

Padilha, José Miguel; Machado, Paulo Puga; Ribeiro, Ana; Ramos, José; Costa, Patrício. (2019). Clinical Virtual Simulation in Nursing Education: Randomized Controlled Trial. J Med Internet Res 2019;21(3):e11529. [doi:10.2196/11529]

Roh YS, Lee W, Chung H, Park Y. (2011). The effects of simulation-based resuscitation training on nurses' self-efficacy and satisfaction. Nurse Educ Today 2013 Feb;33(2):123-128. [doi: 10.1016/j.nedt.2011.11.008] [Medline: 22153054]

Tsai SL, Chai S, Hsieh L, Lin S, Taur F, Sung W, et al. (2008). The use of virtual reality computer simulation in learning Port-A cath injection. Adv Health Sci Educ Theory Pract 2008 Mar;13(1):71-87. [doi: 10.1007/s10459-0069025-3] [Medline: 16944000]

Vaughn J, Lister M, Shaw RJ. (2016). Piloting augmented reality technology to enhance realism in clinical simulation. CIN: Comput Inform Nurs 34(9):402-405

Wilson-Sands C, Brahn P, Graves K. (2015). The effect of instructional method on cardiopulmonary resuscitation skill performance: a comparison between instructor-led basic life support and computer-based basic life support with voiceactivated manikin. J Nurses Prof Dev 2015;31(5):E1-E7. [doi: 10.1097/NND.0000000000000203] [Medline: 26381346] 